\title{
Efficiency for Large Fleets: An Analysis of How Industrial Customers Use Electric and Hybrid Vehicles
}

\author{
Adam-Alexander Manowicz \\ Hochschule Esslingen \\ Kanalstr. 33, 73728 Esslingen, Germany \\ a.manowicz@googlemail.com \\ Jan Frenz \\ Hochschule Esslingen \\ Kanalstr. 33, 73728 Esslingen, Germany \\ Michael Jurenka \\ Hochschule Esslingen \\ Kanalstr. 33, 73728 Esslingen, Germany \\ Rico Meyer \\ Hochschule Esslingen \\ Kanalstr. 33, 73728 Esslingen, Germany \\ Manuel Sessner \\ Hochschule Esslingen \\ Kanalstr. 33, 73728 Esslingen, Germany \\ Paul Stobbe \\ Geotab Inc. \\ 21-1075 North Service Road West, Oakville, Canada
}

\begin{abstract}
This paper presents methods and results which allow an analysis of relevant driving parameters of hybrid and electric vehicles. In order to gain crucial insights into how industrial customers use hybrid and electric vehicles, the paper investigates the following parameters: information about odometer, charging processes and battery charging levels. The data used for this purpose was provided by the Canadian fleet management company Geotab Inc. They were evaluated by means of 'Google BigQuery' and the statistics programme 'IBM SPSS Statistics'. It turned out that correlations between 'charging time' and 'battery charging level' exist, as well as between 'battery level' and 'distance per day'. One of the main questions in the present study asks whether long charging times of car batteries lead to decreased average battery charging levels. As a result of this study, the longer a hybrid vehicle is charged per day, the lower sink its average battery charging level. The findings of this research help managers of car fleets to enhance their existing fleet management for establishing more efficient fleets with respect to ecological and economical aspects. Our research is particularly significant as this will save money across such fleets worldwide, and at the same time, preserve the environment as much as possible.
\end{abstract}

Keywords: fleet management, electric and hybrid vehicles, big data, battery charging

DOI: $10.7176 /$ ISDE/10-3-03

Publication date:March $31^{\text {st }} 2019$

\section{Introduction}

Due to recent considerations of how to create options for more sustainable ways of life, vehicles powered by alternative driving systems play an increasingly important role in our society (Kampker et al. 2018, pp. 143-144). The acceptance of a such new technology by customers is one of most important aspects regarding success. The more knowledge about customer behavior is collected and processed to understand their needs, the better these needs can be used to enhance these technologies. (Manowicz 2018, p. 59) The automotive industry therefore has multiplied efforts to develop and produce significantly higher numbers of electric and hybrid vehicles. It has been projected, for instance, that by 2030, at least 6 million electric vehicles should be circulating on German roads (Propfe et al. 2013, pp. 6-7). Many companies see the changeover to electric vehicles not only as an important asset for the environment, but also as an opportunity to enhance their public image (Globisch et al. 2018, pp. 1011). Wikström et al. (2015, p. 2) state that it is possible to run large fleets of plug-in electric vehicles (PEVs). Consequently, the air quality improves in cities where these fleets are mostly deployed. Further, 'the utilisation degree of vehicles operating in commercial fleets is relatively high and therefore it could therefore [sic] be 
especially beneficial to introduce PEVs owing to their low operational costs' (Wikström et al. 2015, p. 2). In order to gain new insights into how industrial customers use these vehicles, Geotab collects large amounts of data with the help of an OBD II dongle. The analysis and evaluation of the collected data provide the basis to create new solutions for establishing more efficient fleets with respect to ecological and economical aspects.

\section{Literature Review}

Although it has been recognized by representatives of big companies and society at large that alternative driving systems are required to improve ecological efficiency in the automotive industry, tensions and conflicts of interest still exist: on the one hand, the environment needs to be preserved for future generations, and on the other hand, contemporaries wish to see their desires for individual mobility realized. Despite this tension, society, governments and industries need to develop environment-friendly modes of transport and put them into practice. To comply with the need of decreasing emissions and with new regulations and legislation by states across the world, operators of large fleets have had to rethink their strategies. Over the past years, electric and hybrid vehicles have played an increasingly important role, as Mendoza and colleagues state in their article: 'Motivated by stricter environmental regulations, government incentives, branding opportunities, and potential reductions in operational costs, companies all around the world are renewing their fleets with electric vehicles (EVs)' (Mendoza et al. 2018, p. 1). Many companies have begun to introduce alternative modes of driving systems, particularly electric and hybrid engines, in order to reduce emissions. This is true particularly for large fleet operators in urban areas, where it remains a challenge to square the circle between preventing air pollution and keeping both the population and freight traffic on the move, as Foltyński (2014) outlines. National governments have initiated research on this complex issue, projecting electric mobility into the year 2030 (see, for instance, Michaelis et al., n.d.) and discussing as to whether a shift to electric vehicles will benefit the environment (Helms et al., 2015).

Taking this situation as a starting point, the present study investigates the patterns of use of electric and hybrid vehicles by industrial customers. Its innovative potential is to highlight ways in which industrial customers can maximize the use of their changed over fleets. For this, publications and data by Geotab were taken into account. Pilon-Bignell and Milne (2016) come to the conclusion that fleet operators are under pressure to decrease costs for which Geotab offers a solution: they collect and analyse large amounts of data and suggest avenues to more efficiency. As Orlovska (2018) and colleagues as well as Knieps (2018) have argued, 'big data usage can be a solution for user behavior evaluation'. They indicate options to collect data more efficiently and propose to use big data networks including sensors and cameras. Within the larger field of study, this paper contributes novel insights into how patterns of use of electric and hybrid vehicles influence their hardware. In other words, this study reaches original conclusions regarding 'distance per day', 'charging time', and 'battery charging level', and how these parameters interrelate to each other. Through the present study, industrial customers will be enabled to increase the efficiency of their fleets and adjust their management procedures accordingly.

\section{Methodology}

The starting point of the analysis was to go carefully through the dataset offered by the company Geotab in the format of csv-files and to select the most relevant categories for the present investigation. The dataset consists of more than 100.000 .000 entries, which are divided by 14 different parameters. For the present study, relevant entries were selected by employing the powerful data warehouse Google BigQuery. Downsizing the dataset was done in three steps. In the first step, only vehicles sending data about their odometers were taken into account. A further step reduced the sample to include vehicles with data recording their charging processes. Finally, step three reduced this sample of vehicles to those for which details about their odometers, their charging processes and their battery charging level were provided. Following the creation of our data base, these entries were transferred to Microsoft Excel for evaluation.

In order to be able to evaluate the data statistically, certain values relevant to the investigation had to be calculated. The newly calculated values are the driven distance, the number of charging processes, the average charging time, and the average battery charging level. These values were tested with respect to statistical significance by running these through the programme 'IBM SPSS Statistics'. This programme was chosen as it is particularly well adapted to visualize statistical distributions and connections and to carry out additional statistical calculations.

\section{Analysis and Results}

\subsection{Database}

In the statistical analysis, average values of the above-mentioned parameters as well as correlations between different parameters were examined. In other words, only vehicles were included in the analysis for which the entries provide information about odometer, charging processes and battery charging levels. An additional criterion was applied: only vehicles that were used for exactly 365 days were taken into account, the start date for all of these being the 1 st of September 2017. 
Some vehicles displayed an extraordinarily long 'charging time'. As this would impinge the analysis unevenly, the research team decided to treat these as outliers and therefore, to place an upper limit of 1836 minutes to 'charging time' for all vehicles used in the analysis. This corresponds to a charging time of exactly 30.6 hours, the reference value of the maximum charging time of a Tesla Model S on a standard 230V household socket with 16A. According to the prerequisites described above, the following vehicles remain in the data set below (Table 1). Table 1. representative hybrid and electric vehicles of database (Source: Authors).

\begin{tabular}{|l|l|l|l|l|}
\hline Make & Model & Number & Hybrid & Purely electric \\
\hline Chevrolet & Volt & 15 & $\mathrm{x}$ & \\
\hline KIA & Soul EV & 1 & & $\mathrm{x}$ \\
\hline Mitsubishi & Outlander & 73 & $\mathrm{x}$ & \\
\hline Opel & Ampera & 1 & $\mathrm{x}$ & \\
\hline Total & & $\mathbf{9 0}$ & $\mathbf{8 9}$ & $\mathbf{1}$ \\
\hline
\end{tabular}

The two models Volt (Chevrolet) and Outlander (Mitsubishi) represent the main unit of hybrid vehicles in the database. For this reason, only these two models were used for the statistical analysis. They are summarized in Table 2.

Table 2. representative hybrid vehicles of database (Source: Authors).

\begin{tabular}{|l|l|l|l|l|}
\hline Make & Model & Number & Hybrid & Purely electric \\
\hline Chevrolet & Volt & 15 & $\mathrm{x}$ & \\
\hline Mitsubishi & Outlander & 73 & $\mathrm{x}$ & \\
\hline Total & & $\mathbf{8 8}$ & $\mathbf{8 8}$ & $\mathbf{0}$ \\
\hline
\end{tabular}

\subsection{Parameters}

The statistical analysis of these 88 hybrid vehicles examined the parameters 'distance per day', 'charging time' and 'battery charging level'. To calculate the parameters for each selected hybrid vehicle, the following definitions were developed:

$$
\begin{gathered}
\text { Distance per day }=\frac{\text { entire distance }}{365} \\
\text { Charging time }=\frac{\text { entire charging time }}{365}
\end{gathered}
$$

Battery charging level = average of all battery charging levels

The 'entire distance' denotes the sum of all distances (in $\mathrm{km}$ ) travelled by a vehicle during the specified 365days period. The 'entire charging time' sums up the duration of each charging process per vehicle in the 365-day time interval. The 'battery charging level' is defined as the arithmetic means of all battery charging levels of the respective vehicle stored in the dataset over a period of 365 days.

\subsection{Statistical Distributions of Parameters}

The statistical distributions of the selected parameters (described in the methodology section) were, in a first step, graphically determined. Additionally, the arithmetic means of the parameters 'distance per day', 'charging time' and 'battery charging level' were ascertained. The following chart shows the statistical distributions as well as the respective averages of the parameters described above for all examined 88 hybrid vehicles.

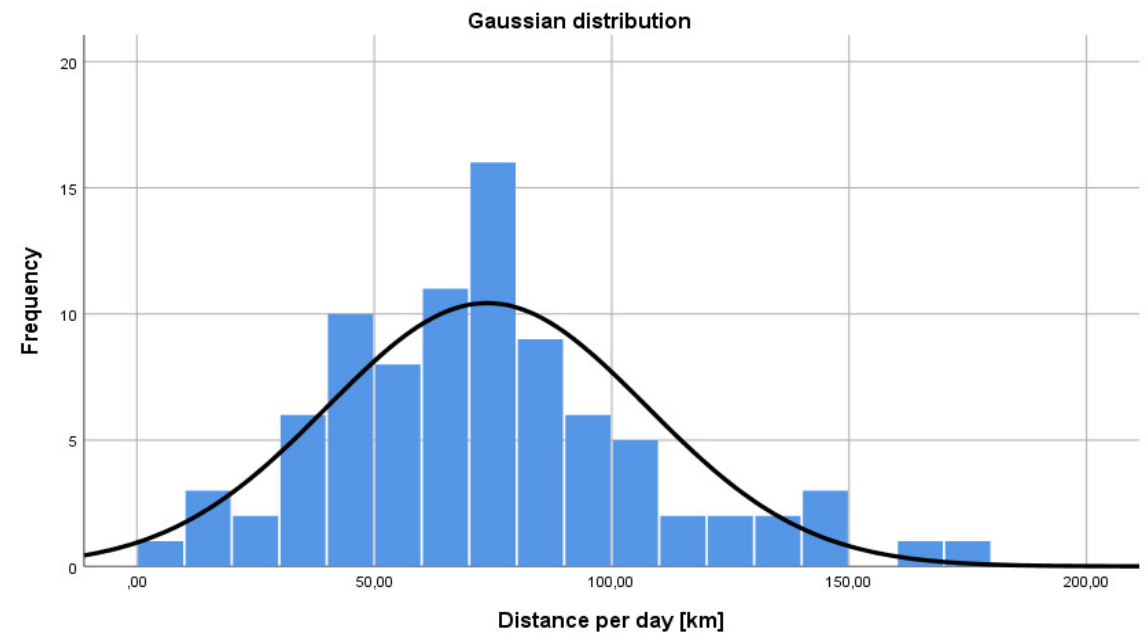

Figure 1: statistical distribution of the driven distance per day for all examined 88 hybrid vehicles (Source: Authors). 
The 88 commercially used hybrid vehicle models Volt (Chevrolet) and Outlander (Mitsubishi) were moved $73.8 \mathrm{~km}$ on average per day.

Table 3. descriptive statistics (Source: Authors).

\begin{tabular}{|l|l|l|l|l|l|}
\hline & Number & Minimum & Maximum & Average & Standard deviation \\
\hline Distance per day in $\mathrm{km}$ & 88 & 5.1 & 176.2 & 73.8 & 33.7 \\
\hline
\end{tabular}

The parameter 'distance per day' of all vehicles used on 365 days was examined comparatively. The information on charging processes and battery charging levels were not taken into account. Instead, only vehicles fitted with odometers and used for exactly 365 days were considered. The dataset shows that 858 vehicles were used 365 days a year. 645 of these are hybrid vehicles, whereas 213 are powered only by electric engines.

Table 4.Vehicles with 'distance per day' (Source: Authors).

\begin{tabular}{|c|c|c|c|c|}
\hline Make & Model & Number & Hybrid & Purely electric \\
\hline Audi & A3 & 5 & $\mathrm{x}$ & \\
\hline Chevrolet & $\begin{array}{l}\text { Malibu } \\
\text { Volt }\end{array}$ & $\begin{array}{l}1 \\
25\end{array}$ & $\begin{array}{l}\mathrm{X} \\
\mathrm{X}\end{array}$ & \\
\hline Ford & $\begin{array}{l}\text { C-Max } \\
\text { C-Max Compact FHEV } \\
\text { C-Max Compact PHEV } \\
\text { Fusion } \\
\text { Taurus }\end{array}$ & $\begin{array}{l}22 \\
212 \\
1 \\
223 \\
1 \\
\end{array}$ & $\begin{array}{l}\mathrm{X} \\
\mathrm{x} \\
\mathrm{x}\end{array}$ & $\mathrm{x}$ \\
\hline GMC & Savana & 1 & $\mathrm{x}$ & \\
\hline Honda & Civic & 6 & $\mathrm{x}$ & \\
\hline Hyundai & $\begin{array}{l}\text { Sonata } \\
\text { Sonata Hybrid }\end{array}$ & $\begin{array}{l}6 \\
4\end{array}$ & $\begin{array}{l}\mathrm{x} \\
\mathrm{x}\end{array}$ & \\
\hline KIA & $\begin{array}{l}\text { Optima } \\
\text { Soul EV }\end{array}$ & $\begin{array}{l}1 \\
1\end{array}$ & $\mathrm{x}$ & $\mathrm{x}$ \\
\hline Lincoln & MKZ & 1 & $\mathrm{x}$ & \\
\hline Mercedes-Benz & S-Klasse & 1 & $\mathrm{x}$ & \\
\hline Mitsubishi & Outlander PHEV & 80 & $\mathrm{x}$ & \\
\hline Opel & Ampera & 1 & $\mathrm{x}$ & \\
\hline Subaru & Impreza & 1 & $\mathrm{x}$ & \\
\hline Toyota & $\begin{array}{l}\text { Avalon } \\
\text { Camry } \\
\text { Highlander } \\
\text { Prius } \\
\text { Prius C } \\
\text { Prius C Hybrid } \\
\text { Prius Plug-In } \\
\text { Prius V }\end{array}$ & $\begin{array}{l}1 \\
29 \\
2 \\
121 \\
57 \\
5 \\
2 \\
21 \\
\end{array}$ & $\begin{array}{l}\mathrm{x} \\
\mathrm{x} \\
\mathrm{x} \\
\mathrm{x} \\
\mathrm{x} \\
\mathrm{x} \\
\mathrm{x} \\
\mathrm{x}\end{array}$ & \\
\hline VW & $\begin{array}{l}\text { Golf } \\
\text { Jetta } \\
\text { Passat } \\
\end{array}$ & $\begin{array}{l}8 \\
2 \\
15 \\
\end{array}$ & $\begin{array}{l}\mathrm{X} \\
\mathrm{X} \\
\mathrm{X}\end{array}$ & \\
\hline Volvo & XC 90 & 2 & $\mathrm{x}$ & \\
\hline Total & & 858 & 645 & 213 \\
\hline
\end{tabular}


The analysis shows the following statistical distribution of the 'distance per day' for all 858 vehicles.

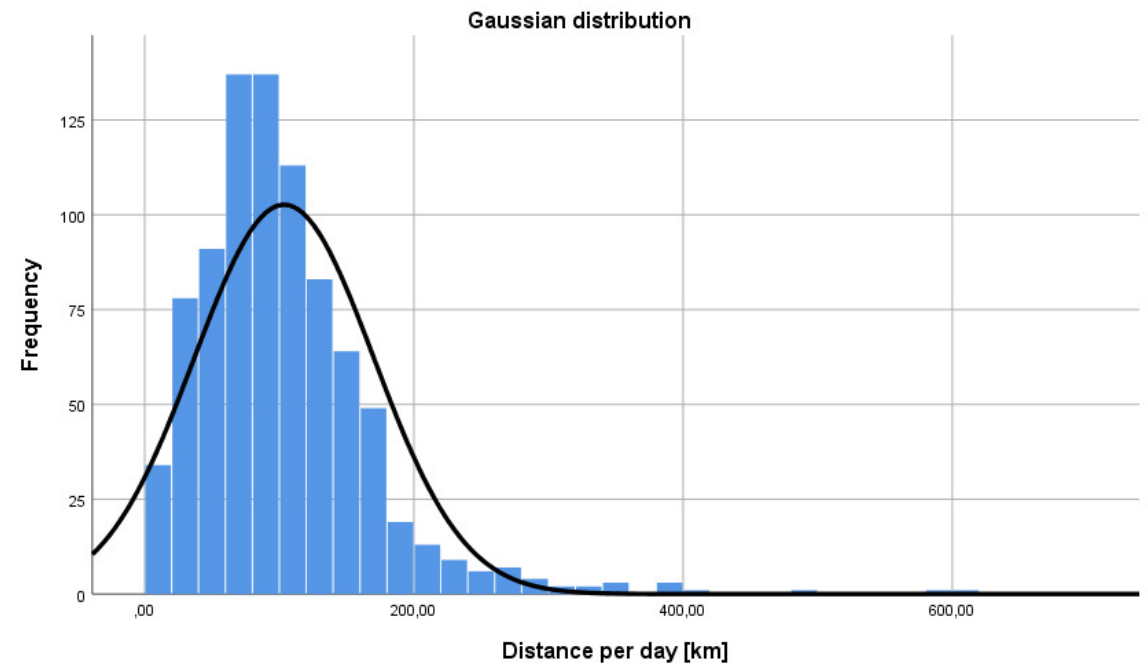

Figure 2: statistical distribution of the driven distance per day for all 858 vehicles (Source: Authors).

The presented calculations lead to the conclusion that the 858 commercially used hybrid and electric vehicles are moved $103.5 \mathrm{~km}$ on average per day.

Table 5. descriptive statistics (Source: Authors).

\begin{tabular}{|l|l|l|l|l|l|}
\hline & Number & Minimum & Maximum & Average & Standard deviation \\
\hline Distance per day in $\mathrm{km}$ & 858 & 4.2 & 609.7 & 103.5 & 66.7 \\
\hline
\end{tabular}

The 88 commercially used hybrid vehicle models Volt (Chevrolet) and Outlander (Mitsubishi) run an average distance of $73.8 \mathrm{~km}$ per day, that is, their average distance is $29.7 \mathrm{~km}$ below the $103.5 \mathrm{~km}$ average distance calculated for all 858 vehicles. With this result they are still within the standard deviation of $66.7 \mathrm{~km}$.

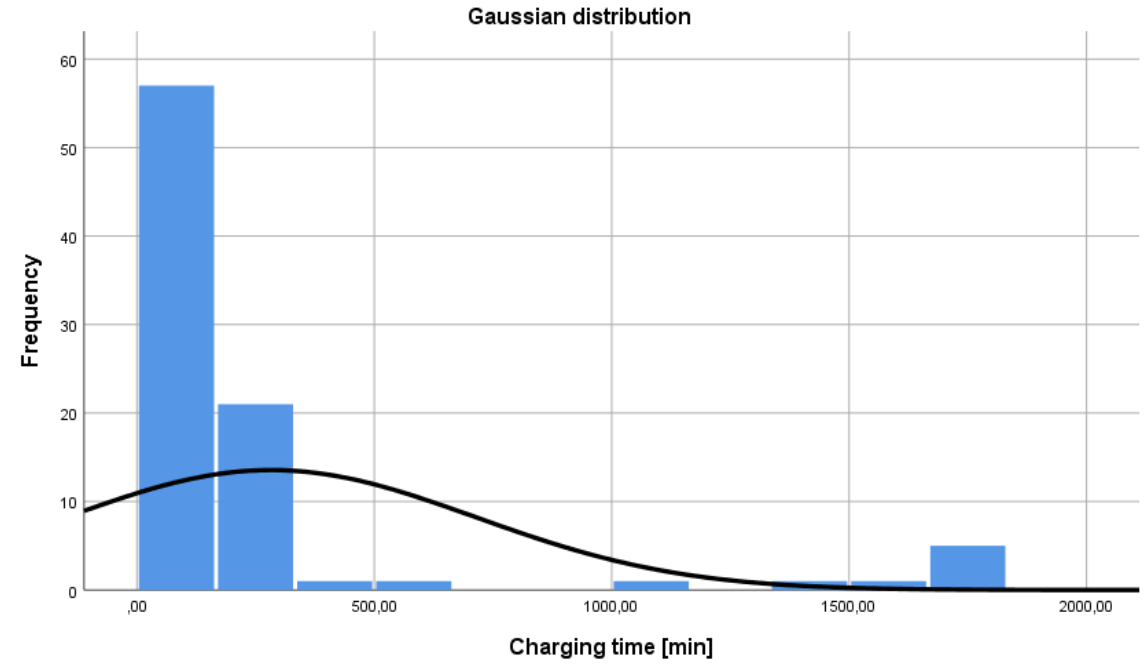

Figure 3: statistical distribution of the charging time for all examined 88 hybrid vehicles (Source: Authors).

The 88 commercially used hybrid vehicle models Volt (Chevrolet) and Outlander (Mitsubishi) are charged $89.1 \mathrm{~min}$ on average per day.

Table 6. descriptive statistics (Source: Authors).

\begin{tabular}{|l|l|l|l|l|l|}
\hline & Number & Minimum & Maximum & Average & Standard deviation \\
\hline Charging time in $\min$ & 88 & 0.4 & 598.0 & 89.1 & 140.1 \\
\hline
\end{tabular}




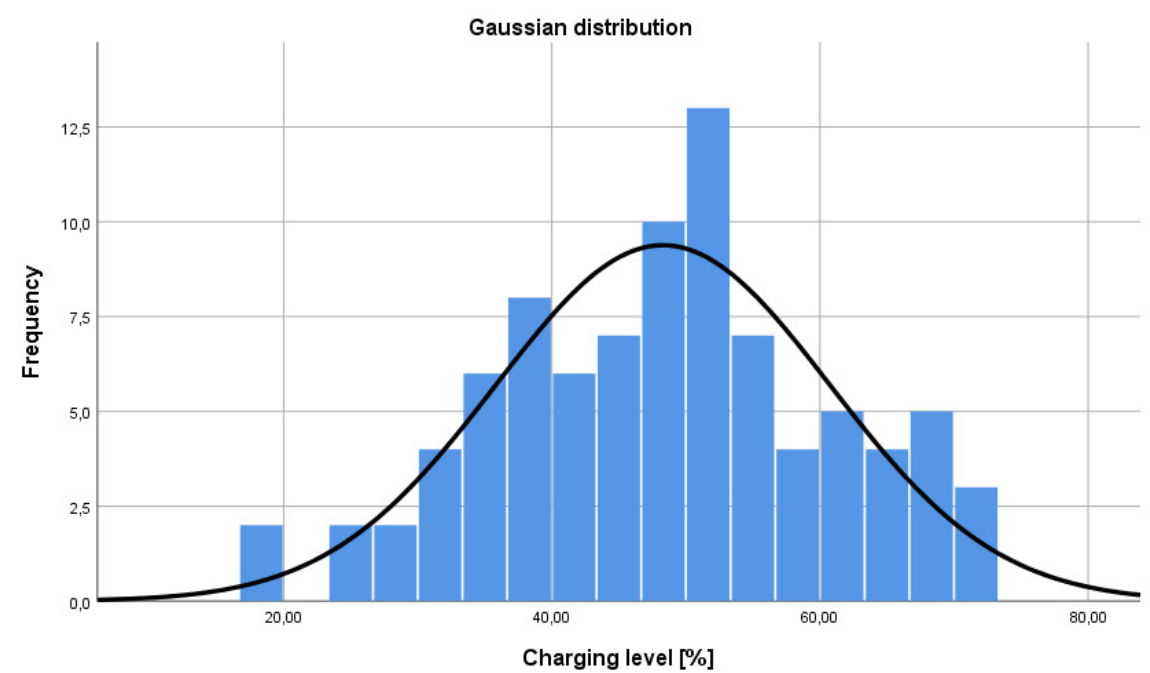

Figure 4: statistical distribution of the charging level for all examined 88 hybrid vehicles (Source: Authors).

The batteries of the 88 commercially used plug-in-hybrid vehicle models Volt (Chevrolet) and Outlander (Mitsubishi) have an average charging level of $48.3 \%$.

Table 7. descriptive statistics (Source: Authors).

\begin{tabular}{|l|l|l|l|l|l|}
\hline & Number & Minimum & Maximum & Average & Standard deviation \\
\hline Battery charging level in \% & 88 & 17.9 & 71.7 & 48.3 & 12.5 \\
\hline
\end{tabular}

\subsection{Test on Normal Distribution}

This test is calibrated to check the statistical distribution of the parameters 'distance per day', 'charging time' and 'battery charging level' with respect to normal distribution (for details on the method, see Bortz et al. 2010, pp. 70-74). The procedure was conducted along the lines of Shapiro-Wilk (for details on the method, see Razali et al. 2011, pp. 21-33). The result - as to whether normal distribution does or does not exist - decided on which procedure was used in the subsequent correlation analysis. In order to be able to decide whether the parameters were to be tested for correlation according to parametric or non-parametric test methods, a test for normal distribution of the underlying data had to be carried out.

The data of the parameters 'distance per day' and 'battery charging level' for the 88 commercially used hybrid vehicle models Volt (Chevrolet) and Outlander (Mitsubishi) are distributed normally, given the statistical significance (for details on the method, see Bortz et al. 2010, pp. 100-102) of 0.080 $>0.05$ and $0.520>0.05$. The data of the parameter 'charging time' are not distributed normally due to a statistical significance of $0.00<0.05$. Table 8. Test on normal distribution (Source: Authors).

\begin{tabular}{|l|l|l|l|}
\hline & Statistics & df & Statistical significance \\
\hline Distance per day & 0.974 & 88 & 0.080 \\
\hline Charging time & 0.598 & 88 & 0.000 \\
\hline Battery charging level & 0.987 & 88 & 0.520 \\
\hline
\end{tabular}

Therefore, the parametric test method according to Pearson (for details on the method, see Fahrmeier et al. 2016, pp. 126-133) was employed for the correlation analysis between 'distance per day' and 'battery charging level'. Spearman's (for details on the method, see Fahrmeier et al. 2016, pp. 133-136) non-parametric correlation method was used for the correlation analysis between 'distance per day' and 'charging time' and between 'charging time' and 'battery charging level'.

\subsection{Testing Correlation between Parameters}

In the next step, the interrelations and correlations between the parameters 'distance per day', 'charging time' and 'battery charging level' were examined. In the case of normal distribution of data, correlations were analysed according to Pearson, and in the opposite case, according to Spearman. The parameters 'distance per day' and 'charging time' hardly correlate with each other: they do so only with a correlation coefficient of -0.062 , calculated according to Spearman. Given the statistical significance of $0.568>0.050$, the null hypothesis 'no correlation' has to be assumed. Thus, the correlation is not significant. 
Table 9. Test on correlation (Source: Authors).

\begin{tabular}{|l|l|l|}
\hline Spearman & & Charging time \\
\hline Distance per day & Correlation coefficient & -0.062 \\
\hline & Statistical significance (2-digits) & 0.568 \\
\hline & Number & 88 \\
\hline
\end{tabular}

The parameters 'charging time' and 'battery charging level' correlate strongly with a correlation coefficient of -0.581 , calculated according to Spearman. Given the statistical significance of $0.000<0.050$, the null hypothesis 'no correlation' has to be rejected. This means that average battery charging levels drop if a vehicle is charged for a long time.

Table 10. Test on correlation (Source: Authors).

\begin{tabular}{|l|l|l|}
\hline Spearman & & Battery charging level \\
\hline Charging time & Correlation coefficient & -0.581 \\
\hline & Statistical significance (2-digits) & 0.000 \\
\hline & Number & 88 \\
\hline
\end{tabular}

The parameters 'battery level' and 'distance per day' correlate moderately with a correlation coefficient of 0.389 , calculated according to Pearson. Given the statistical significance of $0.000<0.050$, the null hypothesis 'no correlation' must be rejected. Thus, the correlation is significant. This means that the distance travelled per day increases, if a vehicle has a high average battery level.

Table 11. Test on correlation (Source: Authors).

\begin{tabular}{|l|l|l|}
\hline Pearson & & Distance per day \\
\hline Battery charging level & Correlation coefficient & 0.389 \\
\hline & Statistical significance (2-digits) & 0.000 \\
\hline & Number & 88 \\
\hline
\end{tabular}

Based on the analysis and the connected calculations the following model was developed:

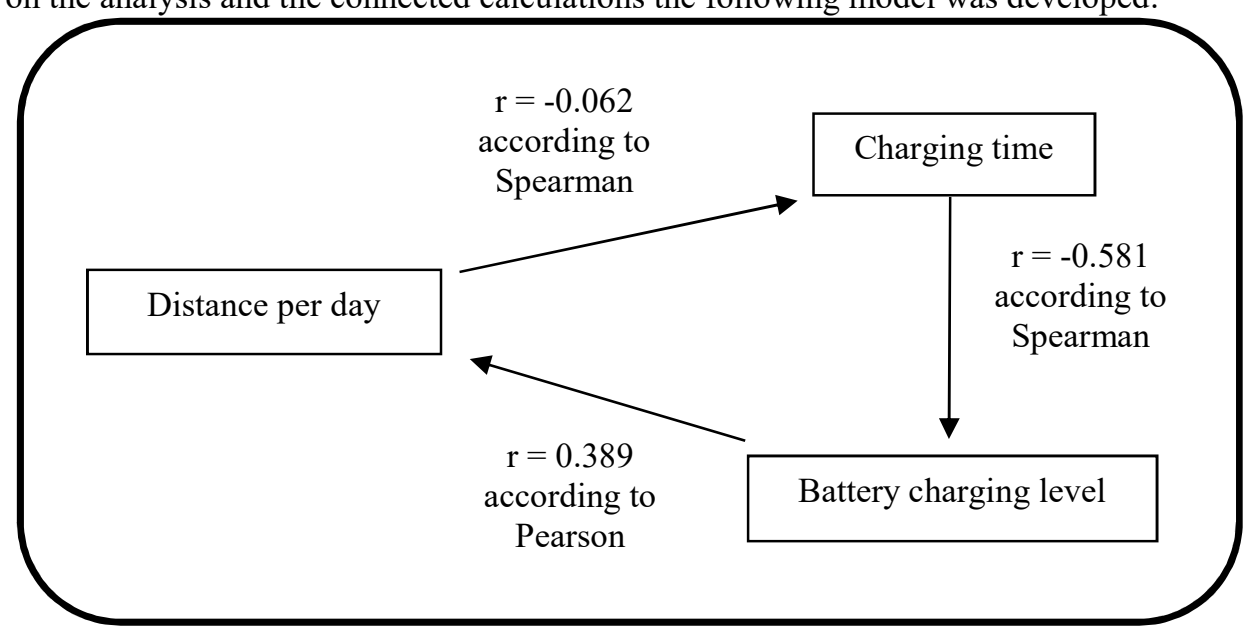

Figure 5: Correlation model (Source: Authors).

\subsection{Comparison of the Vehicle Models}

Finally, the two vehicle models Volt (Chevrolet) and Outlander (Mitsubishi) were compared with each other. The main question was whether the two models show significant differences with respect to certain parameters. The comparison came to the following results: the mean values of the parameter 'distance per day', 'charging processes' and 'charging time' of the two models differed. For this investigation, the parameter 'charging processes' was defined as including all charging processes during the time 365-day period.

Table 12 descriptive statistics Outlander/Mitsubishi (Source: Authors).

\begin{tabular}{|l|l|l|l|l|l|}
\hline & Number & Minimum & Maximum & Average & Standard deviation \\
\hline Distance per day in $\mathrm{km}$ & 73 & 30.7 & 176.2 & 77.8 & 29.8 \\
\hline Charging processes & 73 & 2 & 550 & 113.3 & 100.3 \\
\hline Charging time in min & 73 & 0.4 & 415.9 & 44.2 & 54.1 \\
\hline
\end{tabular}

Table 13. descriptive statistics Volt/Chevrolet (Source: Authors).

\begin{tabular}{|l|l|l|l|l|l|}
\hline & Number & Minimum & Maximum & Average & Standard deviation \\
\hline Distance per day in $\mathrm{km}$ & 15 & 5.1 & 131.5 & 54.0 & 44.5 \\
\hline Charging processes & 15 & 3 & 2459 & 320.5 & 613.8 \\
\hline Charging time in min & 15 & 0.7 & 598.0 & 307.7 & 212.7 \\
\hline
\end{tabular}


In order to verify whether the differences between the arithmetic means of the parameters 'distance per day', 'charging processes' and 'charging time' are statistically significant, the U-test according to Mann-Whitney (for details, see Bortz et al. 2010, pp. 130-133) was applied. Its implementation arrives at the following results. Given the statistical significance values of $0.010<0.050$ and $0.001<0.050$, the null hypothesis 'there is no significant difference' for the parameters 'distance per day' and 'charging time' has to be rejected. This means that the differences between the average values of the parameter 'distance per day' and 'charging time' between the vehicle models Volt (Chevrolet) and Outlander (Mitsubishi) are statistically significant. The Outlander (Mitsubishi) is moved $22.8 \mathrm{~km}$ more on verage per day than the Volt (Chevrolet). In addition, the Volt (Chevrolet) charged about four times longer on average than the Outlander (Mitsubishi). Given the statistical significance of $0.447>0.050$, the null hypothesis 'there is no significant difference' has to be assumed for the parameter 'charging processes'. This means that the difference of the arithmetic mean of the parameter 'charging processes' between the vehicle models Volt (Chevrolet) and Outlander (Mitsubishi) is not statistically significant. Table 14. Mann-Whitney-U test (Source: Authors).

\begin{tabular}{|l|l|l|l|}
\hline & Distance per day & Charging proceses & Charging time \\
\hline Mann-Whitney-U & 316.000 & 479.000 & 235.000 \\
\hline Wilcoxon-W & 436.000 & 3180.000 & 2936.000 \\
\hline Z & -2.569 & -0.760 & -3.468 \\
\hline Asymptotic statistical significance (2-digits) & 0.010 & 0.447 & 0.001 \\
\hline
\end{tabular}

\subsection{Limitations}

Overall, the entries of the Geotab dataset provided odometric values for 858 electric and hybrid vehicles which were used over the time period of 365 days. However, values for 'charging processes' and 'battery charging time' were provided only for 90 models, including Ampera (Opel), Soul EV (KIA), Volt (Chevrolet) and Outlander (Mitsubishi). Therefore, it was not possible to include a larger sample of vehicle models in the analysis with respect to 'charging processes' and 'battery charging time'.

\section{Conclusions}

Increasing efficiency in managing fleets of electric and hybrid vehicles is a crucially important economic aspect for industrial companies and operators. The present paper investigated whether significant interrelations and correlations exist between the parameters 'distance per day', 'charging time' and 'battery charging level' for such vehicles. For this study, large datasets had to be managed and analysed graphically. This was possible through using 'Google BigQuery' and 'IBM SPSS Statistics'.

The results of the analysis highlight the characteristics of electric and hybrid vehicles used 365 days in the time period between the 1st of September 2017 and the 31st of August 2018. These vehicles are moved $103.5 \mathrm{~km}$ per day on average. The average 'charging time' of vehicle models Volt (Chevrolet) and Outlander (Mitsubishi) is 89.1 minutes per day. Their batteries are charged at $48.3 \%$ on average. In addition, a significant correlation exists between the average 'charging time' per day and the average 'battery charging level'. The longer a hybrid vehicle is charged per day, the lower sink its average 'battery charging level'. Additionally, higher average 'battery charging levels' allows driving longer distances per day. Based on the results it is necessary that managers of fleets control the 'charging time' of their commercially used electric and hybrid vehicles closely.

In sum, the analysis of how industrial customers and fleet operators use their electric and hybrid vehicles provides significant insights. It also allows developing new solutions and strategies to increase the efficiency of managing large fleets of industrial customers. This scientific investigation acts as a spring board for further research in the field of increasing the efficiency in managing large fleets, both in terms of economic and ecological benefits. There are various possibilities in which directions future research could go. For instance, it would be fascinating to include improvements of the technology of cars, such as develop batteries that have a much longer life, and thus be more environmentally friendly in the production process. This would enable customers to plan their itineraries with more flexibility as batteries will not have to be charged as frequently; this in turn would again increase the efficiency for fleet managers. There is an array of further research options, however, setting all of them out requires another research paper.

\section{References}

Bortz, J. \& Schuster, C. (2010): Statistik für Human- und Sozialwissenschaftler. 7th edition. Berlin: SpringerVerlag.

Fahrmeir, L. \& Heumann, C. \& Künstler, R. \& Pigeot, I. \& Tutz, G. (2016): Statistik: Der Weg zur Datenanalyse. 8th edition. Berlin: Springer-Verlag.

Foltyński, M. (2014): Electric Fleets in Urban Logistics. In: Procedia - Social and Behavioral Sciences, Volume 151, 30 October 2014, Pages 48-59.

Globisch, J. \& Dütschke, E. \& Wietschel, M. (2018). Adoption of electric vehicles in commercial fleets: Why do 
car pool managers campaign for BEV procurement? In: Transportation Research Part D: Transport and Environment, October 2018, pp. 122-133.

Helms, H. \& Jöhrens, J. \& Kämper, C. \& Giegrich, J. \& Liebich, A. \& Vogt, R. \& Lambrecht, U. (2015): Weiterentwicklung und vertiefte Analyse der Umweltbilanz von Elektrofahrzeugen. ifeu - Institut für Energieund Umweltforschung Heidelberg GmbH (im Auftrag des Umweltbundesamtes).

Kampker, A. \& Vallée, D. \& Schnettler, A. (eds) (2018): Elektromobilität: Grundlagen einer Zukunftstechnologie. 2nd edition. Berlin: Springer-Verlag.

Knieps, G. (2018): Internet of Things, big data and the economics of networked vehicles. In: Telecommunications Policy, 27 September 2018.

Manowicz, A.A. (2018): Impact of Connected Remote Services on Car Servicing Loyalty. In: European Journal of Business and Management, Vol.10, No.8, pp. 59-69.

Mendoza, J. \& Montoya, A. \& Guéret, C. \& Villegas, J. (2018): Routing a hybrid fleet of conventional and electric vehicles: the case of a French utility. In: Odysseus 2018, Jun 2018, Cagliari, Italy.

Michaelis, J. \& Helms, H. \& Noeren, D. \& Dallmer-Zerbe, K. \& Gnann, T. \& Haendel, M. \& Reinhard, C. \& Marwitz, S. (n. d.): Energie und Umwelt. Elektromobilität in Baden-Württemberg im Jahr 2013. Projektübergreifende Forschung im Schaufenster Elektromobilität Baden-Württemberg. Abschlussbericht.

Orlovska, J. \& Wickman, C. \& Söderberg, R. (2018): Big Data Usage Can Be a Solution for User Behavior Evaluation: An Automotive Industry Example. In: Procedia CIRP, Volume 72, 2018, Pages 117-122.

Pilon-Bignell, J. \& Milne, A. (2016): Increasing Profitability with Telematics. Publishing house and location not given.

Propfe, B. \& Kreyenberg, D. \& Wind, J. \& Schmid, S. (2013): Market penetration analysis of electric vehicles in the German passenger car market towards 2030. In: International Journal of Hydrogen Energy, May 1, 2013, pp. 5201-5208.

Razali, N. M., \& Wah, Y. B. (2011): Power comparisons of Shapiro-Wilk, Kolmogorov-Smirnov, Lilliefors and Anderson-Darling tests. In: Journal of Statistical Modeling and Analytics, January, 2011, Malaysia, pp. 2133.

Stenner, F. (ed.) (2009): Handbuch Automobilbanken. Finanzdienstleistungen für Mobilität. Berlin: SpringerVerlag.

Wikström, M. \& Hansson L. \& Alvfors, P. (2015): An End has a Start - Investigating the Usage of Electric Vehicles in Commercial Fleets. In: Energy Procedia, August 2015, pp. 1932-1937. 